\title{
$\gamma$-tocotrienol inhibits the invasion and migration of human gastric cancer cells through downregulation of cyclooxygenase- 2 expression
}

\author{
YA HUI ZHANG $^{1 *}$, KE MA $^{2 *}$, JIA REN LIU ${ }^{3}$, HAI XIA WANG ${ }^{1}$, \\ WEN XIA TIAN ${ }^{1}$, YUE HUA TU ${ }^{1}$ and WEN GUANG SUN ${ }^{1}$ \\ Departments of ${ }^{1}$ Clinical Nutrition and ${ }^{2}$ Emergency, Shanghai Jiao Tong University \\ Affiliated Sixth People's Hospital, Shanghai 200233; ${ }^{3}$ Department of Clinical Laboratory, \\ Harbin Medical University Affiliated Fourth People's Hospital, Harbin, Heilongjiang 150001, P.R. China
}

Received October 13, 2017; Accepted June 4, 2018

DOI: 10.3892/or.2018.6497

\begin{abstract}
T3), a tocotrienol isoform belonging to the vitamin $\mathrm{E}$ family, has been revealed to exert inhibitory effects on proliferation, migration and invasion in human gastric cancer cells. However, its precise mechanism of action is still unclear and needs to be further tested. Cyclooxygenase-2 (COX-2) is well known for its key role in promoting the migration and invasion abilities of human gastric cancer cells. In light of these data, our study aimed to validate whether the inhibitory actions of $\gamma$-T3 could be achieved by downregulation of COX-2 activity in vitro. In the present study, a Cell Counting Kit-8 (CCK-8) assay was performed to observe proliferation in human gastric cancer cells (SGC-7901 and MGC-803 cells), and wound healing and Transwell chamber assays were performed to detect migration and invasion. Western blot analyses were performed to analyse the relative expression of COX-2, matrix metalloproteinases-2 and -9 (MMP-2 and MMP-9) proteins, and enzyme-linked immunosorbent assays (ELISA) were used to determine the exocrine roles of MMP-2 and MMP-9. The results revealed that $\gamma$-T3 exerted significant inhibitory effects on proliferation, migration, invasion and COX-2 protein expression, as well as on exocrine functions of MMP-2 and MMP-9 in SGC-7901
\end{abstract}

Correspondence to: Professor Wen Guang Sun, Department of Clinical Nutrition, Shanghai Jiao Tong University Affiliated Sixth People's Hospital, 600 Yishan Road, Shanghai 200233, P.R. China

E-mail: sunwenguang68@126.com

*Contributed equally

Abbreviations: $\gamma$-T3, $\gamma$-tocotrienol; COX-2, cyclooxygenase-2; CCK-8, Cell Counting Kit-8; MMP-2 and MMP-9, matrix metalloproteinases-2 and -9; ELISA, enzyme-linked immunosorbent assay

Key words: migration, invasion, COX-2, human gastric cancer cells, MMPs and MGC-803 cells. Therefore, our results indicated that $\gamma$-T3 exerts inhibitory effects on migration and invasion, which may be mediated through downregulation of COX-2 expression in SGC-7901 and MGC-803 cells.

\section{Introduction}

Gastric cancer is one of the most commonly diagnosed cancers worldwide $(1,2)$. Currently, while radical surgery is the most common and effective treatment, the prognosis of patients with advanced gastric cancer following curative resection remains poor. The 5-year survival rate of patients with gastric cancer is $27.4 \%$ after surgical resection (3). There is no denying that proliferation, invasion and metastasis of cancer cells lead to poor prognoses, which presents therapeutic challenges. The major causes of death for gastric cancer patients are liver metastases and peritoneal metastases (4). Prevention of tumour recurrence and metastasis must urgently be improved. Available evidence has demonstrated that certain nutrients and non-nutrients derived from foods, such as phytochemicals (4-8) and vitamins (9-11), have protective effects against cancer.

Consumption of vitamin $\mathrm{E}$, one of the most widely consumed vitamins, is prevalent because of its antioxidant capacity and multiple health benefits. Tocotrienols, isoforms of the vitamin E family, can be derived from several plant species, including palm oil, wheat germ, barley and bran oil. It should be noted that the antitumour properties of vitamin $\mathrm{E}$ (8-10) have been a hot topic in recent years, which may make tocotrienols a promising group of drugs for future development $(12,13)$.

Cyclooxygenase-2 (COX-2), an important isoform of the COX family, is well known for its close relationship to tumourigenesis, invasiveness, inflammatory response, angiogenesis and tumour cell growth (14). It has been reported that COX-2 is continuously expressed and is closely associated with the invasiveness and metastasis of gastric cancer cells (15). COX-2 promotes the development and metastasis of gastric cancer cells. Furthermore, there are several other types of tumours in which COX-2 is highly expressed, such as oesophageal, 
liver, lung and breast cancer, as well as other gastrointestinal cancers (16-20).

Matrix metalloproteinases (MMPs) can degrade nearly all types of ECM proteins, and they destroy histologic barriers during the processes of invasion and metastasis (15). In addition, MMP-9 and MMP-2 have been reported to be overexpressed and associated with tumour migration and invasion $(21,22)$. Notably, there is an intimate connection between MMPs and the mechanism by which COX-2 regulates tumour metastasis (15).

Although recent studies have revealed that $\gamma$-T3 displays inhibitory effects on the migration and invasion of human gastric cancer cells, the specific mechanism remains unclear (9). Our present study demonstrated that compared to $\gamma$-T3 alone, combination of $\gamma$-T3 and $N$-[2-(cyclohexyloxy)-4-nitropheny]methane sulphonamide (NS-398, a highly selective inhibitor of COX-2) did not significantly alter the exocrine levels of MMP-2 and MMP-9 in gastric adenocarcinoma cell lines. Thus, it was concluded that the reduction of COX-2 resulting from $\gamma$-T3 was likely to be the cause that inhibited the invasion and migration of SGC-7901 and MGC-803 cells.

\section{Materials and methods}

Chemicals and cell lines. $\gamma$-Tocotrienol $(\gamma$-T3) $(\geq 97 \%)$ was purchased from Hygeia Industries Inc. (Wilmette, IL, USA). $\gamma$-T3 was dissolved in ethanol (95\%) to produce a $104 \mu \mathrm{mol} / 1$ solution and was stored at $-20^{\circ} \mathrm{C}$. A Cell Counting Kit-8 (CCK-8) was purchased from Dojindo Molecular Technologies, Inc. (Kumamoto, Japan). RPMI-1640 medium, fetal bovine serum (FBS), $0.25 \%$ EDTA and penicillin/ streptomycin were purchased from Gibco; Thermo Fisher Scientific, Inc. (Waltham, MA, USA). anti-COX-2 (1:1,000; cat. no. 4842), anti-MMP-2 (1:1,000; cat. no. 4022), antiMMP-9 (1:1,000; cat. no. 3852) and anti- $\beta$-actin antibodies, along with NS-398, were purchased from Cell Signaling Technology Inc. (Danvers, MA, USA). NS-398 was prepared in a range of concentrations.

Cell culture. Human gastric cancer cell lines SGC-7901 and MGC-803 were purchased from the Cancer Institute of the Chinese Academy of Medical Sciences (Beijing, China). The two cell lines were cultured at $37^{\circ} \mathrm{C}$ in a $5 \% \mathrm{CO}_{2}$ incubator in 100-mm culture dishes with RPMI-1640 medium supplemented with $10 \%$ FBS and $1 \%$ penicillin/streptomycin. Upon reaching $\sim 70-80 \%$ confluence, the cells were trypsinized using a mixture of $0.25 \%$ trypsin and EDTA, and then logarithmic phase cells were selected for subsequent experiments.

CCK-8 assay. The proliferation of SGC-7901 and MGC-803 cells treated with various concentrations of $\gamma-\mathrm{T} 3$ or NS-398 was detected by CCK- 8 assays. Briefly, $1 \times 10^{4}$ cells/well $(100 \mu \mathrm{l})$ were seeded in 96-well microtiter plates. After incubation overnight, the cells were changed to fresh culture medium (2\% FBS) containing $0,15,30,45$ and $60 \mu \mathrm{mol} / 1$ of $\gamma$-T3, or $0,25,50,75$ and $100 \mu \mathrm{mol} / 1 \mathrm{NS}-398$. After incubation for 24,48 or $72 \mathrm{~h}, 10 \mu \mathrm{l}$ of CCK-8 was added to each well. After incubating for another $4 \mathrm{~h}$, the absorbance values in each well were measured at a wavelength of $450 \mathrm{~nm}$ on a microplate reader (ELx800; BioTek Instruments, Inc., Winooski, VT,
Table I. The $\mathrm{IC}_{50}$ values in SGC-7901 and MGC-803 cells treated with $\gamma$-T3 for different durations.

\begin{tabular}{lccc}
\hline & \multicolumn{3}{c}{$\mathrm{IC}_{50}(\mu \mathrm{mol} / \mathrm{l})$} \\
\cline { 2 - 4 } Cells & $24 \mathrm{~h}$ & $48 \mathrm{~h}$ & $72 \mathrm{~h}$ \\
\hline SGC-7901 & $54.14 \pm 1.06$ & $35.77 \pm 1.05$ & $27.07 \pm 1.08$ \\
MGC-803 & $58.34 \pm 1.05$ & $42.59 \pm 1.05$ & $21.10 \pm 1.09$
\end{tabular}

USA). Cell viability was assessed with blank controls as $100 \%$ to calculate the percentage of control.

Scratch wound healing assay. SGC-7901 or MGC-803 cells were seeded in 6 -well plates at $5 \times 10^{5}$ cells/well overnight in a humidified incubator with an atmosphere of $5 \% \mathrm{CO}_{2}$ at $37^{\circ} \mathrm{C}$. After pretreatment with $30 \mu \mathrm{mol} / 1$ of $\gamma$-T3 for $24 \mathrm{~h}$, a sterile $200 \mu$ l Eppendorf tip was used to scratch the cells in the plates, which were then washed with PBS three times and placed in fresh serum-free RPMI-1640 medium for 24 and $48 \mathrm{~h}$. The distance of wound healing was recorded. Three random fields were selected for examination and were photographed with an inverted microscope (magnification, x100).

Transwell invasion assay. Cell invasion assays were conducted in Transwell chambers (Corning, Acton, MA, USA) with 8- $\mu \mathrm{m}$ pores containing Matrigel in a 24 -well plate, as previously described (23). Briefly, SGC-7901 or MGC-803 cells were treated with $\gamma$-T3 $(0,15,30,45$ and $60 \mu \mathrm{mol} / \mathrm{l})$ for $24 \mathrm{~h}$ and were then trypsinized and resuspended in serum-free RPMI-1640 medium. The cells were added into the upper chamber at $2 \times 10^{5}$ cells/well in $200 \mu \mathrm{l}$ serum-free RPMI-1640 medium. RPMI-1640 medium containing 10\% FBS (500 $\mu \mathrm{l})$ was added into the lower chamber. After incubation for $48 \mathrm{~h}$, the non-invasive cells in the inside membrane of the chamber were scraped off with a sterile cotton swab. The cells in the outer membrane of the chamber, which had passed through the Matrigel, were washed three times with PBS, fixed with $4 \%$ formaldehyde for $20 \mathrm{~min}$ and stained with crystal violet for $20 \mathrm{~min}$. Cells located on the underside of the filter were photographed and counted with an inverted microscope (magnification, $\mathrm{x} 200$ ). The results were expressed as the number of cells that had invaded through the Matrigel within each field.

Western blot analysis. To determine the levels of COX-2, MMP-2 and MMP-9 protein expression, total protein was extracted from SGC-7901 and MGC-803 cells using cell lysis buffer containing protease inhibitors (both from Cell Signaling Technology, Inc.). Total protein determination and gel electrophoresis were performed as described in our previous studies (24). The blots were incubated with anti-COX-2 (1:1,000; cat. no. 4882) anti-MMP-2 (1:1,000; cat. no. 4042), anti-MMP-9 (1:1,000; cat. no. 3852) or anti- $\beta$-actin primary antibodies, and goat anti-rabbit horseradish peroxidase (HRP) secondary antibodies (1:8,000; cat. no. A9169) (Sigma-Aldrich, St. Louis, MO, USA). Target protein bands in membranes were visualized using enhanced chemiluminescence (Thermo Fisher Scientific, Inc.). The relative expression of the three 

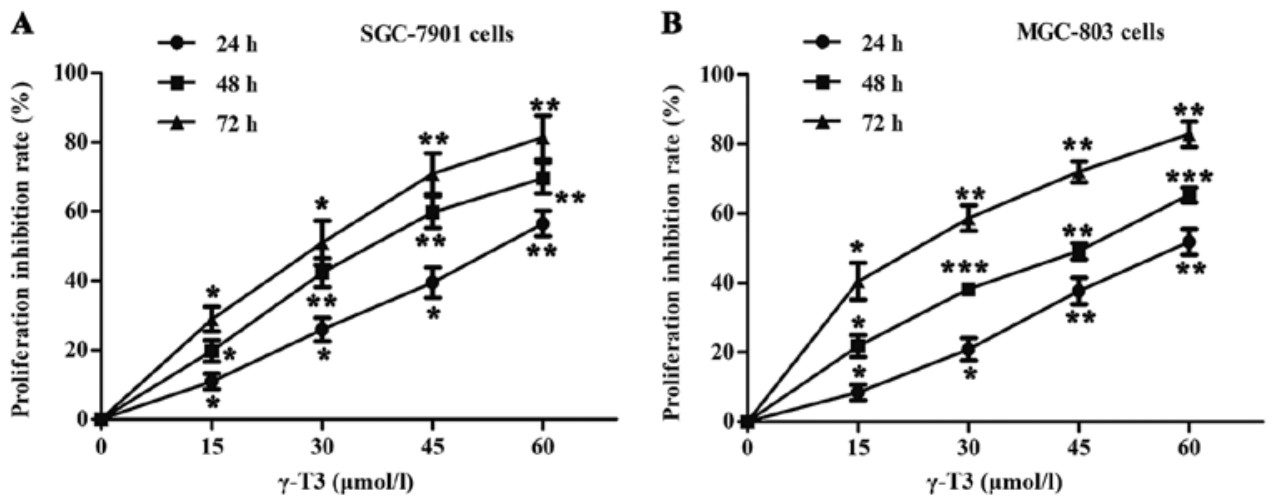

Figure 1. The inhibitory rates of SGC-7901 and MGC-803 cells. Cells were seeded in 96-well plates. After overnight incubation, different concentrations of $\gamma$-T3 were added to each well. Cell viability was determined using CCK-8 assays. The inhibitory rates of (A) SGC-7901 and (B) MGC-803 cells were calculated and plotted. ${ }^{*} \mathrm{P}<0.05,{ }^{* *} \mathrm{P}<0.01$ and ${ }^{* * *} \mathrm{P}<0.001$ vs. the control. $\gamma$-T3, $\gamma$-tocotrienol; CCK-8, Cell Counting Kit-8.

A

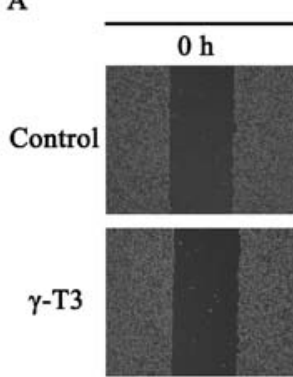

$\mathrm{C}$

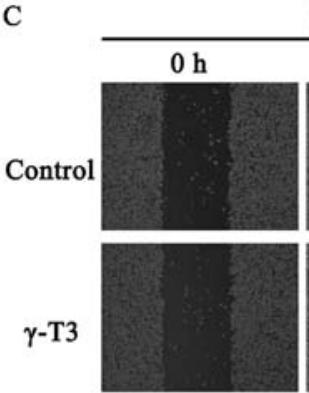

SGC-7901 cells

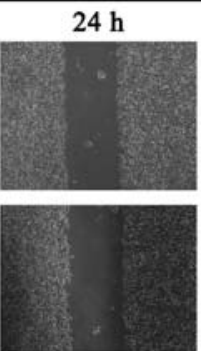

MGC-803 cells
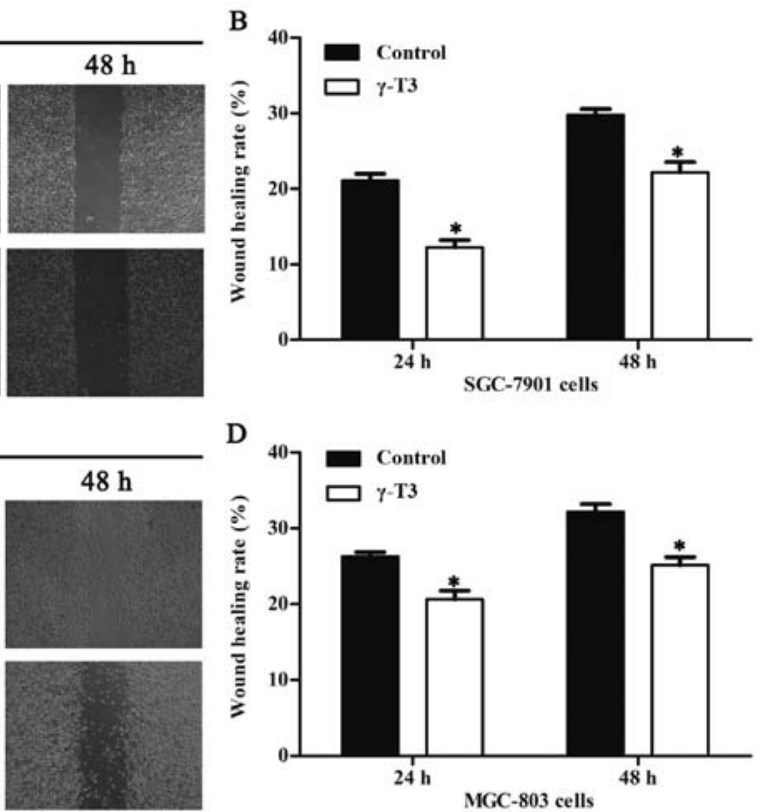

Figure 2. $\gamma$-T3 inhibits the migration ability of SGC-7901 and MGC-803 cells. Cells were seeded in 6-well plates. (A and C) After pretreatment with $30 \mu$ mol/1 of $\gamma$-T3, the monolayer of SGC-7901 or MGC-803 cells was scratched and fresh serum-free RPMI-1640 medium was added for 24 or $48 \mathrm{~h}$. (B and D) The migration distances were calculated from images captured under an inverted microscope. ${ }^{*} \mathrm{P}<0.05$ vs. the control. $\gamma$-T3, $\gamma$-tocotrienol.

aforementioned proteins was assessed using $\beta$-actin as an internal standard.

Enzyme-linked immunosorbent assay (ELISA). To further determine whether $\gamma$-T3, NS-398 or $\gamma$-T3 combined with NS-398 inhibited exocrine functions of MMP-9 and MMP-2 in SGC-7901 and MGC-803 cells, culture supernatants were examined using ELISA assays. Supernatants were collected from SGC-7901 and MGC-803 cells after treatment with $\gamma$-T3 $(0,15,30,45$ or $60 \mu \mathrm{mol} / \mathrm{l}), \mathrm{NS}-398(100 \mu \mathrm{mol} / \mathrm{l})$ or $\gamma$-T3 combined with NS-398 (30 and $100 \mu \mathrm{mol} / 1$, respectively) for $24 \mathrm{~h}$. The concentrations of MMP-9 and MMP-2 in the supernatants were detected according to the ELISA kit protocol. Optical density values were acquired using a microplate reader. Final values were calculated by subtracting the optical density at $570 \mathrm{~nm}$ from that at $450 \mathrm{~nm}$. Each sample was assessed at least three times. Concentrations of MMP-9 and MMP-2 were calculated with a standard curve.
Statistical analysis. All experiments were independently performed at least three times, and data were expressed as the means \pm SD. Differences between $\gamma$-T3-treated and control groups were analysed using Student's t-test or one-way analysis of variance (ANOVA) followed by Dunnett's post hoc test using SPSS 16.0 (SPSS, Inc., Chicago, IL, USA) and GraphPad Prism 5.0 (GraphPad Software, Inc., La Jolla, CA, USA). The grey values of protein bands were analysed by ImageJ software. Differences were considered statistically significant at $\mathrm{P}<0.05$.

\section{Results}

$\gamma-T 3$ inhibits the proliferation of SGC-7901 and MGC-803 cells. As shown in Fig. 1, the rates of cell proliferation were determined by CCK-8 assays in SGC-7901 and MGC-803 cells. $\gamma$-T3 significantly inhibited the proliferation of SGC-7901 and MGC-803 cells treated with different concentrations of $\gamma$-T3 
A

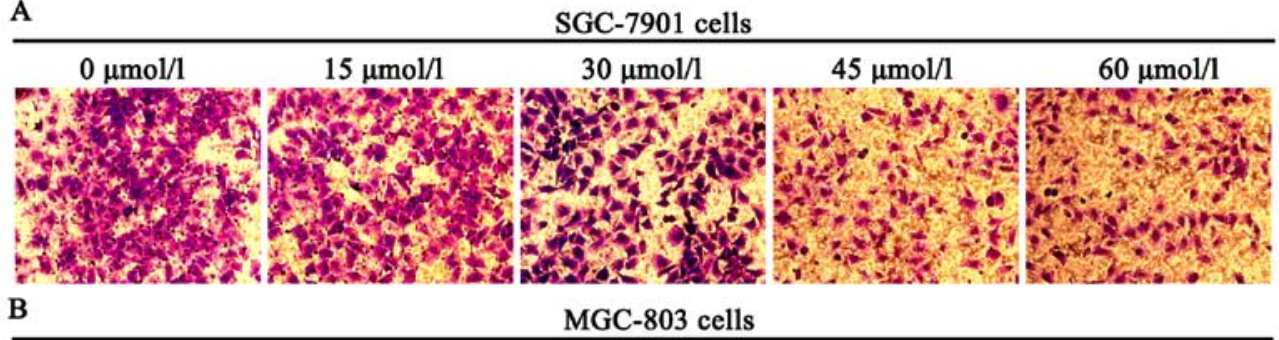

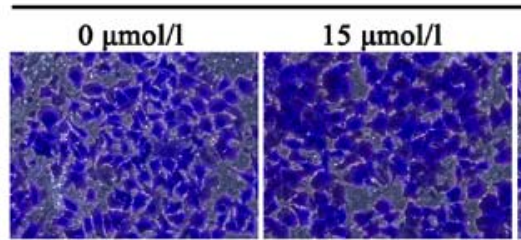

C

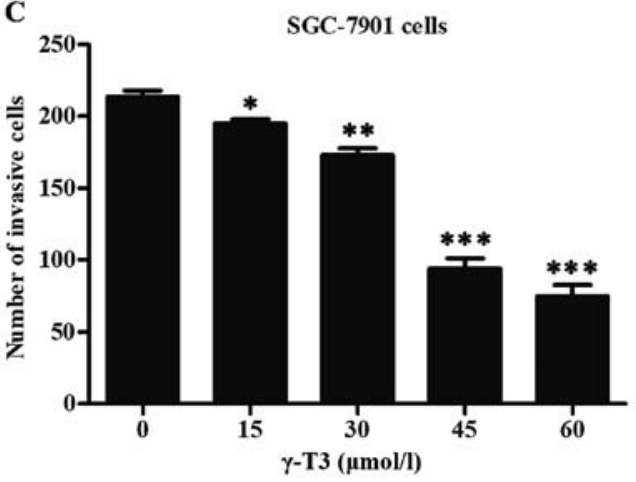

$30 \mu \mathrm{mol} / 1$

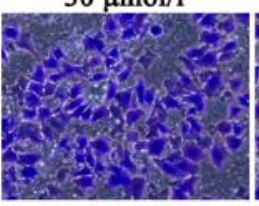

D

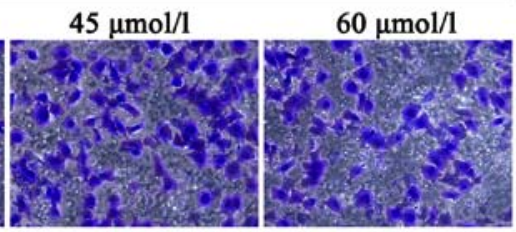

MGC-803 cells

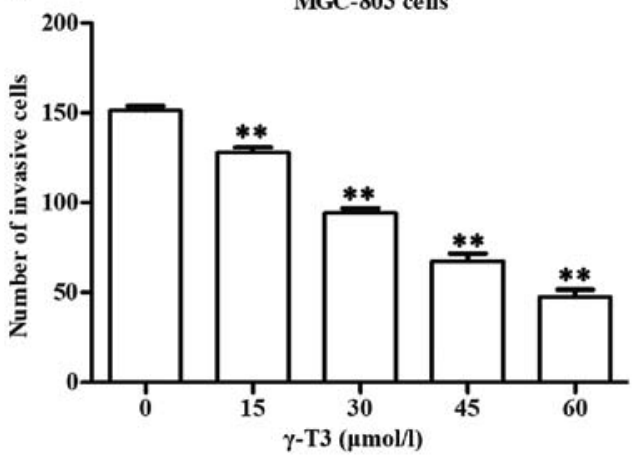

Figure 3. $\gamma$-T3 inhibits the invasion abilities of SGC-7901 and MGC-803 cells. (A and C) SGC-7901 and (B and D) MGC-803 cells were treated with different concentrations of $\gamma-\mathrm{T} 3(0,15,30,45$ and $60 \mu \mathrm{mol} / \mathrm{l})$ for $24 \mathrm{~h}$. The cells were observed for their invasion ability using Transwell chambers. ${ }^{*} \mathrm{P}<0.05{ }^{* *} \mathrm{P}<0.01$ and **** $\mathrm{P}<0.001$ vs. the control. $\gamma$-T3, $\gamma$-tocotrienol.

$(0,15,30,45$ or $60 \mu \mathrm{mol} / 1)$ in a time- and dose-dependent manner $(\mathrm{P}<0.05, \mathrm{P}<0.01$ and $\mathrm{P}<0.001$, respectively) (Fig. 1). The $\mathrm{IC}_{50}$ values were also calculated for cells treated with $\gamma$-T3 for 24,48 or $72 \mathrm{~h}$ (Table I).

$\gamma-T 3$ inhibits the migration and invasion of SGC-7901 and $M G C-803$ cells. According to the $\mathrm{IC}_{50}$ values, $30 \mu \mathrm{mol} / 1$ of $\gamma$-T3 evidently did not affect proliferation of these cells. Consequently, $30 \mu \mathrm{mol} / 1 \gamma$-T3 was chosen to test cell migration in wound healing assays. The results revealed that $\gamma$-T3 notably inhibited the migration ability of SGC-7901 and MGC-803 cells after treatment for 24 and $48 \mathrm{~h}$ compared with that of the control group $(\mathrm{P}<0.05$, Fig. 2$)$. To analyse the effects of $\gamma$-T3 on gastric cancer cell invasion, the Transwell chamber assay was also employed for this experiment. The invasive ability of SGC-7901 and MGC-803 cells was quantified as the number of tumour cells passing through the microporous membrane. $\gamma$-T3 significantly decreased the number of invasive cells $(\mathrm{P}<0.05, \mathrm{P}<0.01$ and $\mathrm{P}<0.001$; Fig. 3 ), which indicated that $\gamma$-T3 inhibited the invasion of gastric cancer cells.

$\gamma$-T3 inhibits the expression of $C O X-2$, matrix metalloproteinases-2 and -9 (MMP-2 and MMP-9) in SGC-7901 and MGC-803 cells. To assess the effects of $\gamma-\mathrm{T} 3$ on the expression of COX-2, MMP-2 and MMP-9, western blot analyses were performed with proteins from SGC-7901 and MGC-803 cells treated with different concentrations of $\gamma$-T3 for $24 \mathrm{~h}$. As shown in Fig. 4, $\gamma$-T3 significantly decreased the expression of COX-2, MMP-2 and MMP-9 in gastric cancer cells in a dosedependent manner $(\mathrm{P}<0.05$ or $\mathrm{P}<0.01$ and $\mathrm{P}<0.001)$.

$\gamma-T 3$ inhibits exocrine levels of MMP-2 and MMP-9 in $S G C-7901$ and MGC-803 cells. To further detect exocrine levels of MMP-2 and MMP-9, cell supernatants were explored by ELISA. The results revealed that $\gamma$-T3 significantly inhibited secretion of MMP-2 and MMP-9 in SGC-7901 and MGC-803 cells $\left(\mathrm{P}<0.05\right.$ or $\mathrm{P}<0.01$ and $\left.{ }^{* * *} \mathrm{P}<0.001\right)$ (Fig. 5). Thus, $\gamma$-T3 inhibited not only intracellular expression of MMP-2 and MMP-9, but also secretion of MMP-2 and MMP-9 in SGC-7901 and MGC-803 cells.

$\gamma$-T3 $(30 \mu \mathrm{mol} / \mathrm{l})$ combined with NS-398 (100 $\mu \mathrm{mol} / \mathrm{l})$ does not significantly alter the exocrine levels of MMP-9 and MMP-2 in SGC-7901 and MGC-803 cells. In light of the aforementioned data, we utilized ELISA assays to further investigate whether $\gamma$-T3 could affect the exocrine levels of MMP-9 and MMP-2 in SGC-7901 and MGC-803 cells when combined with $100 \mu \mathrm{mol} / 1 \mathrm{NS}-398$. This concentration of NS-398 maximized the inhibitory effect on COX-2 (Fig. 7A and C) and did not have adverse effects on the cells according to the instructions and the CCK-8 assay (Fig. 6). In addition, $30 \mu \mathrm{mol} / 1$ $\gamma$-T3 in $24 \mathrm{~h}$ had no evident actions on the proliferation of SGC-7901 and MGC-803 cells (Table I). Thus, we selected $100 \mu \mathrm{mol} / 1 \mathrm{NS}-398$ to ascertain whether combination with $30 \mu \mathrm{mol} / 1 \gamma$-T3 affected the exocrine levels of MMP-9 and 
A

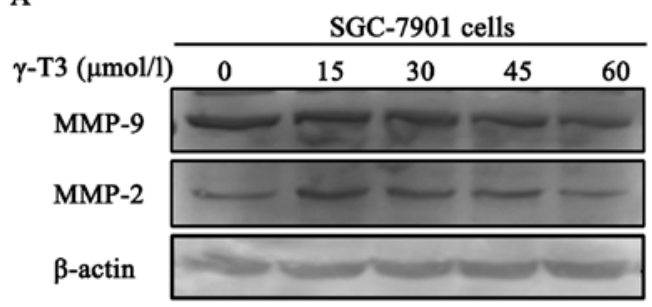

C

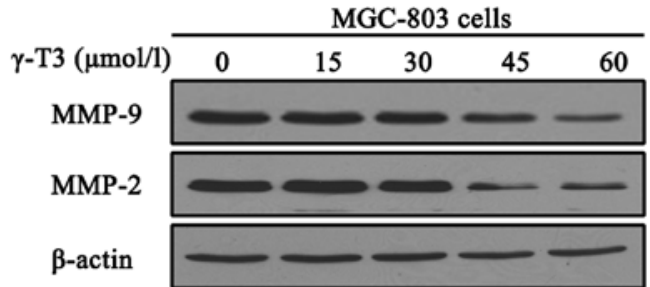

E

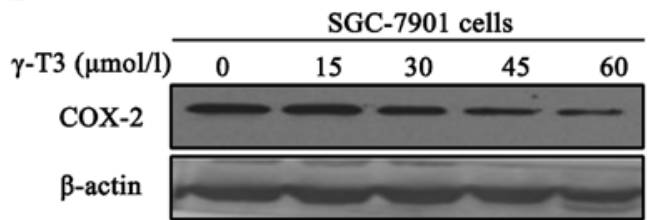

G

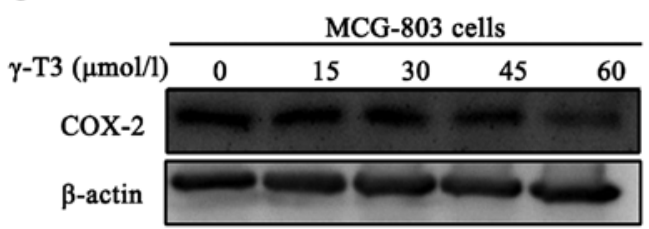

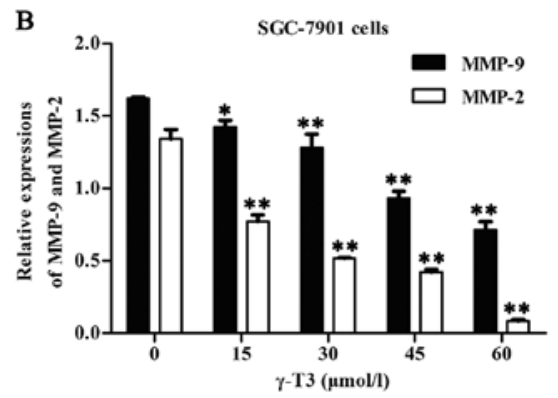
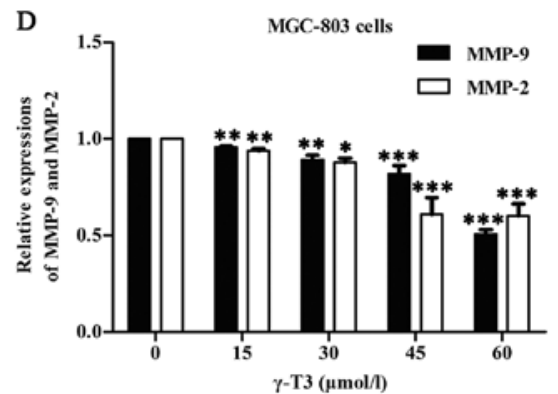

F SGC-7901 cells
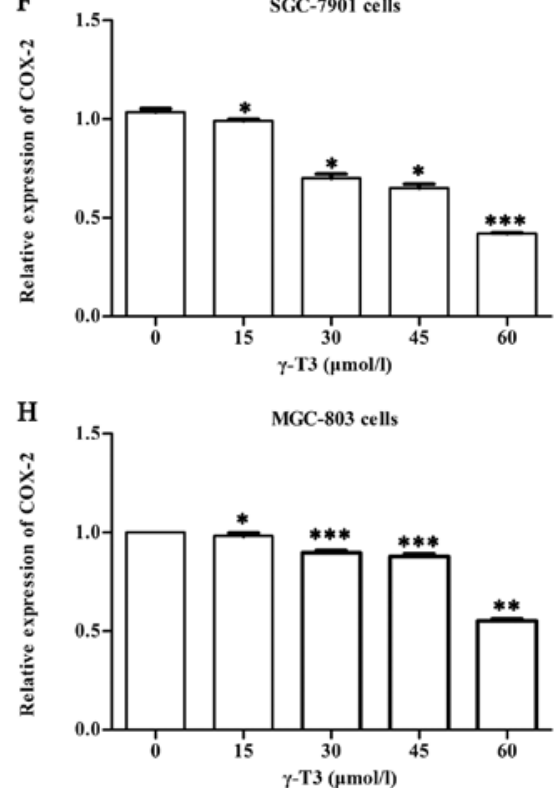

Figure 4. $\gamma$-T3 inhibits the expression of COX-2, MMP-9 and MMP-2 in SGC-7901 and MGC-803 cells. (A-D) The expression of MMP-9, MMP-2 in SGC-7901 and MGC-803 cells. (E-H) The expression of COX-2 in SGC-7901 and MGC-803 cells. Proteins were isolated after cells were treated with $\gamma$-T3 $(0,15,30,45$ and $60 \mu \mathrm{mol} / \mathrm{l})$ for $24 \mathrm{~h}$. Changes in MMP-9, MMP-2 and COX-2 expression were assessed using western blotting. ${ }^{*} \mathrm{P}<0.05,{ }^{* *} \mathrm{P}<0.01$ and ${ }^{* * *} \mathrm{P}<0.001 \mathrm{vs}$. the control. COX-2, cyclooxygenase-2; $\gamma$-T3, $\gamma$-tocotrienol.

MMP-2 in SGC-7901 and MGC-803 cells. Compared to the control, the $30 \mu \mathrm{mol} / 1 \gamma$-T3 group, $100 \mu \mathrm{mol} / 1 \mathrm{NS}-398$ group, and $30 \mu \mathrm{mol} / 1 \gamma-\mathrm{T} 3+100 \mu \mathrm{mol} / 1 \mathrm{NS}-398$ group exhibited a significant declining trend $(\mathrm{P}<0.05$ or $\mathrm{P}<0.01)$. However, compared to the $30 \mu \mathrm{mol} / 1 \gamma$-T3 group alone, the $30 \mu \mathrm{mol} / 1$ $\gamma$-T3 $+100 \mu \mathrm{mol} / 1 \mathrm{NS}-398$ group exhibited no statistical significance $(\mathrm{P}>0.05)$.

\section{Discussion}

Gastric cancer is the second leading cause of malignant tumours worldwide (25). Chemotherapy is an important treatment method, but it frequently leads to poor effects or failure due to multidrug resistance (MDR). As a result, the discovery of novel therapeutic methods to solve these problems is extremely urgent. Furthermore, since invasion and metastasis are two important characteristics that can determine the effects of cancer diagnosis and prognosis (26), it has become crucial to take effective measures to increase prevention of gastric cancer.

$\gamma$-T3, a member of the vitamin E family, has been demonstrated to inhibit proliferation and induce apoptosis, as well as exhibit superior inhibition of migration and invasion in tumour cells $(8,9)$. These antitumour properties explain why $\gamma$-T3 has received so much attention in recent years. In this study, we also obtained evidence that $\gamma$-T3 inhibits the invasion and migration of human gastric cancer cells.

COX-2 is an induced form of cyclooxygenase that is often elevated in cancerous tissues (27). It is well known for accelerating the invasion and migration of tumour cells, making it 

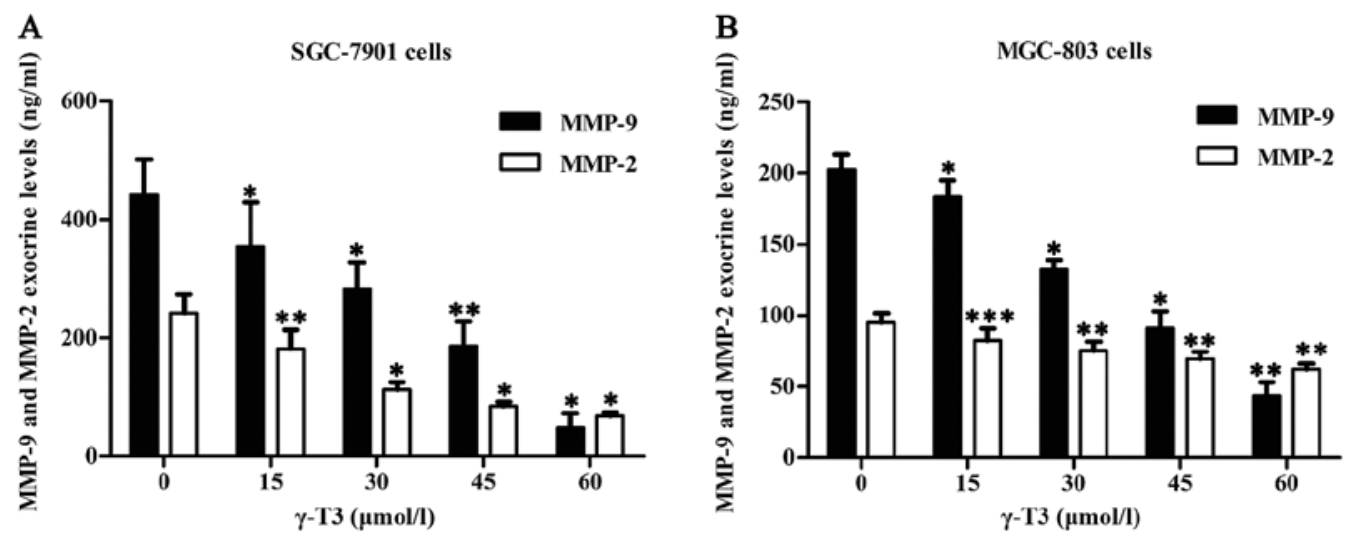

Figure 5. Effects of $\gamma$-T3 on the exocrine levels of MMP-9 and MMP-2 in SGC-7901 and MGC-803 cells. Following $\gamma$-T3 treatment $(0,15,30,45$ and $60 \mu$ mol/l) for $24 \mathrm{~h}$, the cell culture supernatants were collected, and the exocrine levels of MMP-2 and MMP-9 were determined using ELISA. (A) The exocrine levels of MMPs in SGC-7901 cells. (B) The exocrine levels of MMPs in MGC-803 cells. ${ }^{*} \mathrm{P}<0.05,{ }^{* *} \mathrm{P}<0.01$ and ${ }^{* * *} \mathrm{P}<0.001$ vs. the control. $\gamma$-T3, $\gamma$-tocotrienol.

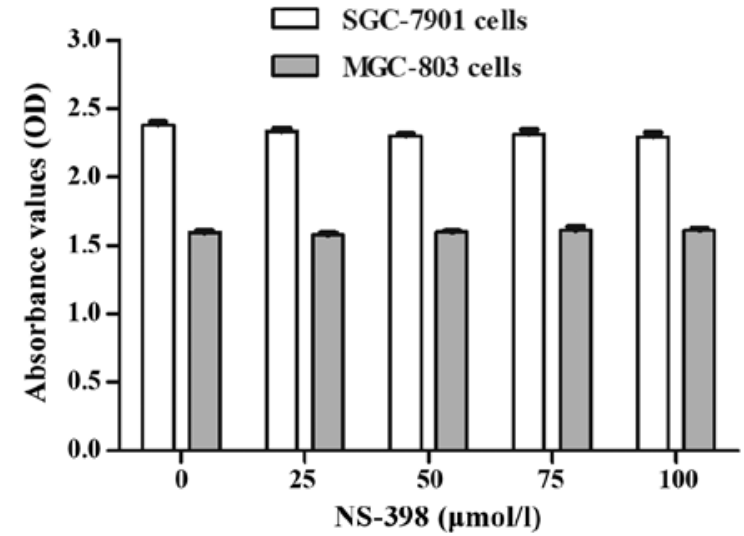

Figure 6. NS-398 does not exert evident change on the proliferation of gastric cancer cells. SGC-7901 and MGC-803 cell lines were cultured in 96-well plates for $24 \mathrm{~h}$, and then different concentrations $(0,25,50,75$ and $100 \mu \mathrm{mol})$ of NS-398 were added to each well. After $24 \mathrm{~h}$ of NS-398 treatment, the absorbance values $(\mathrm{OD})$ were detected with a microplate reader. Each experiment was carried out at least three times.

a research hot topic in recent years (28). Recent studies have confirmed that COX-2 plays an important role in the invasion and metastasis of gastric cancer cells, and it has been suggested that reducing the expression of COX-2 in tumour cells may attenuate invasion and metastasis $(29,30)$.

MMP-9, also known as 92-kDa type IV collagenase, is an enzyme belonging to the family of zinc-metalloproteinases. MMP-9 is involved in the breakdown of the extracellular matrix in normal physiological processes, such as angiogenesis, wound healing and cell migration, as well as in metastasis. MMP-2, also known as $72-\mathrm{kDa}$ type IV collagenase and gelatinase $\mathrm{A}$, is associated with processes such as cancer progression, cancer cell invasion, cell signalling, neovascularization and lymphangiogenesis. Metastasis and invasion are among the leading causes of death among gastric cancer patients (31). MMPs can be activated to destroy the basement membrane, resulting in the degradation of the extracellular matrix, thus opening channels for invasion and metastasis $(15,32)$.

Both SGC-7901 (moderately differentiated) and MGC-803 (undifferentiated or poorly differentiated) belong to gastric adenocarcinoma cell lines. COX-2 can be expressed in the two cell lines, and the level of COX-2 in SGC-7901 cells is higher than in MGC-803 cells $(33,34)$. In the present study, scratch wound healing and Transwell invasion assays demonstrated that $\gamma$-T3 treatment markedly inhibited the migration and invasion of SGC-7901 and MGC-803 cells (Figs. 2 and 3). Western blot analyses in the present study revealed that the expression of COX-2 and intracellular MMPs was decreased (Fig. 4). ELISA data revealed that the exocrine concentrations of MMPs in cell culture supernatants also exhibited a decreasing trend after SGC-7901 and MGC-803 cells were pretreated with $\gamma$-T3 for 24 h (Fig. 5). Notably, it has been revealed that overexpression of COX-2 is involved in the induction of MMPs (15). Thus, in light of our data, we speculated whether the decreases of COX-2 resulted in the exocrine levels of MMPs. Next, to determine whether these inhibitory effects on migration and invasion were associated with COX-2, we utilized NS-398 for verification. NS-398, a highly selective inhibitor of COX-2, was chosen for joint treatment with $\gamma$-T3, and the results were determined using ELISA assays. We noticed that the exocrine level of MMP-2 in Fig. 5A was higher than that in Fig. 7F. The cause of this is that cancer cells from different generations may exert different experimental outcomes. Compared to $\gamma$-T3 alone, $\gamma$-T3 in combination with $100 \mu \mathrm{mol} / 1$ NS-398 did not significantly alter the exocrine expression of MMP-9 and MMP-2 (P>0.05, Fig. 7). These findings indicated that the decrease in the exocrine levels of MMPs were likely to result from downregulation of $\mathrm{COX}-2$, but the exact mechanism involved in the downregulation of MMPs by COX-2 remained unknown. The ELISA assay results were compatible with our hypothesis that the decreases of COX-2 were involved in the induction of MMPs in human gastric cancer cells. The data gathered in the present study suggest, at least in part, that the inhibitory effects on migration and invasion in treated SGC-7901 and MGC-803 cells ( $\gamma$-T3 alone or combined with NS-398) may be associated with downregulation of COX-2.

In conclusion, the present study demonstrated that $\gamma$-T3 significantly inhibited migration and invasion of human gastric cancer cells via downregulation of COX-2 expression, making it a promising novel drug for future cancer treatment. The antitumour efficacy of $\gamma$-T3 may make a difference in the treatment and prevention of gastric cancer. Although we 
A

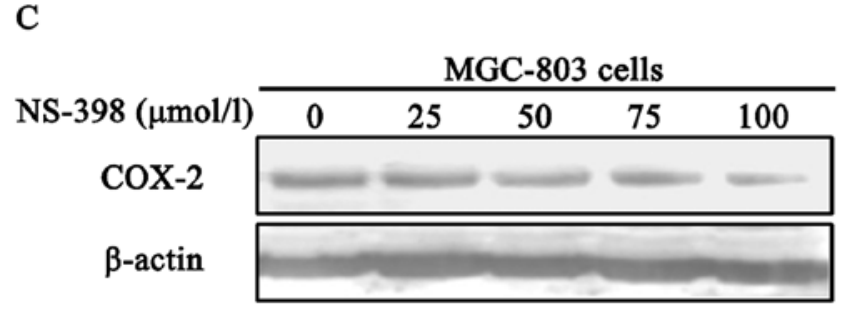

$\mathrm{E}$

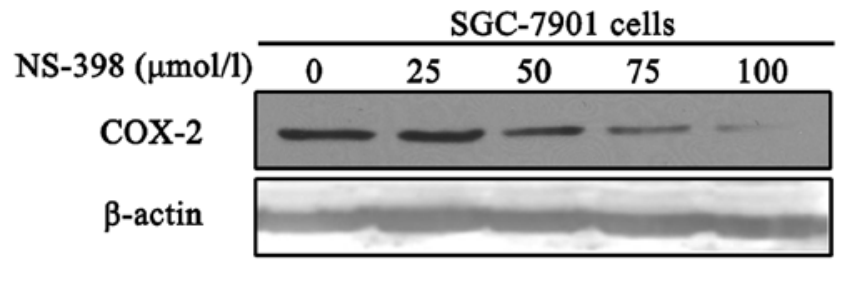

F

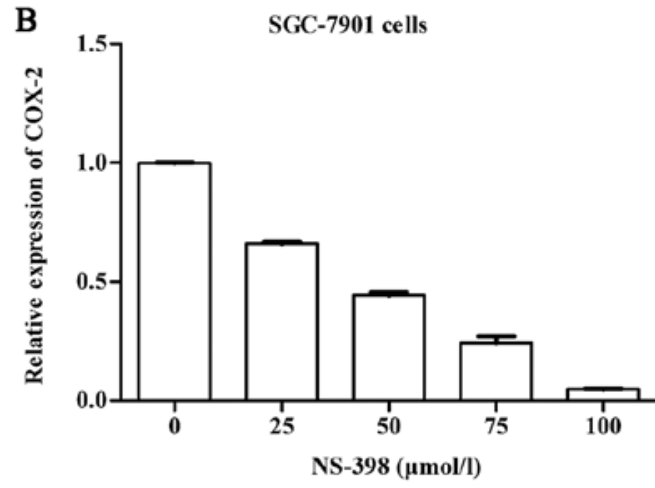

D MGC-803 cells
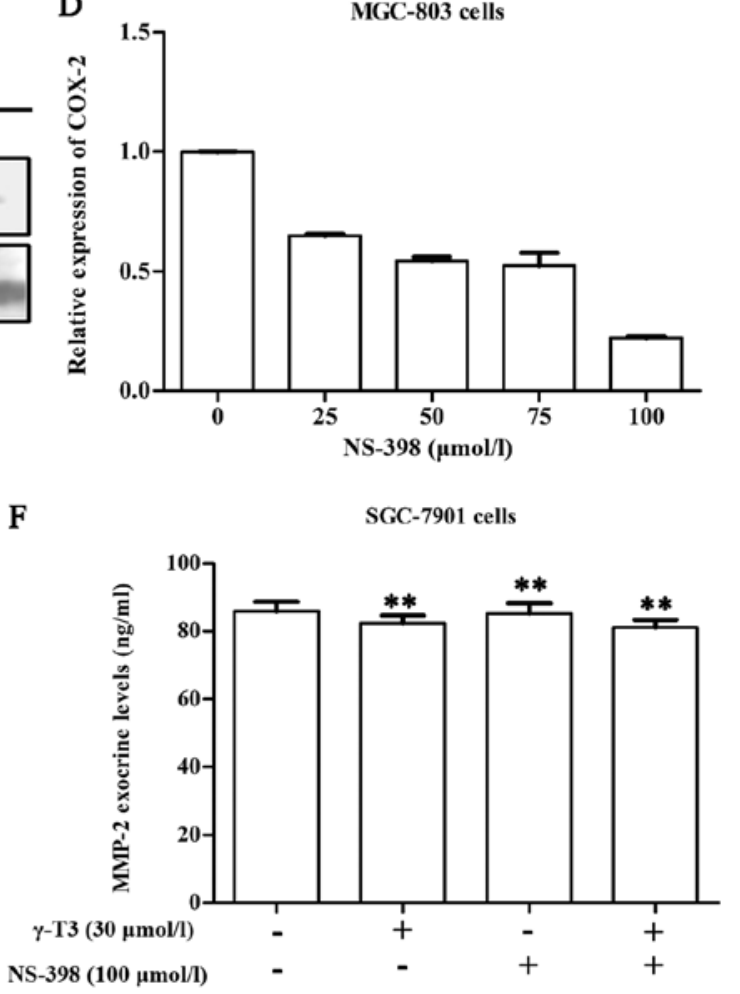

$\mathrm{H}$

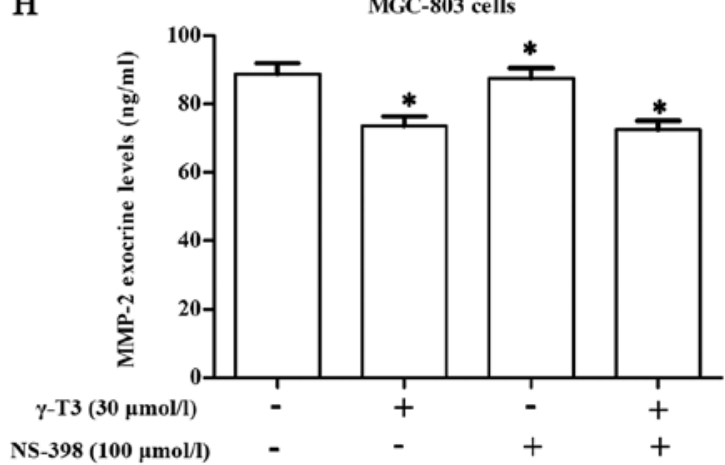

Figure 7. $\gamma$-T3 in combination with NS-398 does not significantly alter the exocrine levels of MMP-9 and MMP-2 in SGC-7901 and MGC-803 cells. (A-D) The expression of COX-2 in gastric cancer cells after being treated with NS-398 $(0,25,50,75$ and $100 \mu \mathrm{mol} / \mathrm{l})$. (E-H) The effects of $30 \mu \mathrm{mol} / 1 \gamma$-T3, $100 \mu \mathrm{mol} / 1$ NS-398 and $30 \mu \mathrm{mol} / 1 \gamma$-T3 combined with $100 \mu \mathrm{mol} / 1$ NS-398 on the levels of MMP-9 and MMP-2 in SGC-7901 and MGC-803 cells. Culture supernatants were collected after cells were treated with $30 \mu \mathrm{mol} / 1 \gamma$-T3, $100 \mu \mathrm{mol} / 1 \mathrm{NS}-398$ or $30 \mu \mathrm{mol} / 1 \gamma$-T3 combined with $100 \mu \mathrm{mol} / 1 \mathrm{NS}-398$ for $24 \mathrm{~h}$. Combination of $30 \mu \mathrm{mol} / 1 \gamma$-T3 with $100 \mu \mathrm{mol} / 1 \mathrm{NS}-398$ exhibited no increase in the inhibitory effect compared to $30 \mu \mathrm{mol} / 1 \gamma-\mathrm{T} 3$ alone. ${ }^{*} \mathrm{P}<0.05$ and ${ }^{* *} \mathrm{P}<0.01$ vs. the control. COX-2, cyclooxygenase- $2 ; \gamma$-T3, $\gamma$-tocotrienol.

have explored the inhibitory potential of $\gamma$-T3 on migration and invasion in human gastric cancer cells in vitro, these experiments are insufficient to explain the mechanism by which $\gamma$-T3 acts. This drawback is also a limitation of our study that can be improved in future research. Accordingly, further research must be performed in mouse models in vivo 
to illustrate our results obtained in SGC-7901 and MGC-803 cells in vitro.

\section{Acknowledgements}

Not applicable.

\section{Funding}

The present study was supported by the National Natural Science Foundation of China (no. 81273061).

\section{Availability of data and materials}

The datasets used and analyzed during the current study are available from the corresponding author on reasonable request.

\section{Authors' contributions}

YHZ and KM carried out all the experiments and YHZ was responsible for drafing the manuscript. WGS was responsible for the study design. JRL, HXW, WXT and YHT were responsible for data collection and analysis. All authors read and approved the manuscript and agree to be accountable for all aspects of the research in ensuring that the accuracy or integrity of any part of the work are appropriately investigated and resolved.

\section{Ethics approval and consent to participate}

Not applicable.

\section{Patient consent for publication}

All authors carefully and critically reviewed the submitted manuscript and agreed to the final version for publication.

\section{Competing interests}

The authors declare that they have no competing interests.

\section{References}

1. Jemal A, Bray F, Center MM, Ferlay J, Ward E and Forman D: Global cancer statistics. CA Cancer J Clin 61: 69-90, 2011.

2. Torre LA, Bray F, Siegel RL, Ferlay J, Lortet-Tieulent J and Jemal A: Global cancer statistics, 2012. CA Cancer J Clin 65: 87-108, 2015.

3. Zeng H, Zheng R, Guo Y, Zhang S, Zou X, Wang N, Zhang L, Tang J, Chen J, Wei K, et al: Cancer survival in China, 2003-2005: A population-based study. Int J Cancer 136: 1921-1930, 2015.

4. Hu X: Risk factors and prognosis of liver metastasis from gastric cancer. Zhonghua Wei Chang Wai Ke Za Zhi 17: 108-111, 2014 (In Chinese).

5. Chen HS, Liu M, Shi LJ, Zhao JL, Zhang CP, Lin LQ, Liu Y, Zhang SJ, Jin JC, Wang L, et al: Effects of raspberry phytochemical extract on cell proliferation, apoptosis, and serum proteomics in a rat model. J Food Sci 76: T192-T198, 2011.

6. Dong HW, Zhang S, Sun WG, Liu Q, Ibla JC, Soriano SG, Han XH, Liu LX, Li MS and Liu JR: $\beta$-Ionone arrests cell cycle of gastric carcinoma cancer cells by a MAPK pathway. Arch Toxicol 87: 1797-1808, 2013.

7. Liu Q, Dong HW, Sun WG, Liu M, Ibla JC, Liu LX, Parry JW, Han XH, Li MS and Liu JR: Apoptosis initiation of $\beta$-ionone in SGC-7901 gastric carcinoma cancer cells via a PI3K-AKT pathway. Arch Toxicol 87: 481-490, 2013.
8. Liu Y, Liu M, Li B, Zhao JL, Zhang CP, Lin LQ, Chen HS, Zhang SJ, Jin JC, Wang L, et al: Fresh raspberry phytochemical extract inhibits hepatic lesion in a Wistar rat model. Nutr Metab (Lond) 7: 84, 2010.

9. Liu HK, Wang Q, Li Y, Sun WG, Liu JR, Yang YM, Xu WL, Sun XR and Chen BQ: Inhibitory effects of gamma-tocotrienol on invasion and metastasis of human gastric adenocarcinoma SGC-7901 cells. J Nutr Biochem 21: 206-213, 2010.

10. Zhang JS, Li DM, Ma Y, He N, Gu Q, Wang FS, Jiang SQ, Chen BQ and Liu JR: $\gamma$-Tocotrienol induces paraptosis-like cell death in human colon carcinoma SW620 cells. PLoS One 8: e57779, 2013

11. Zhang JS, Zhang SJ, Li Q, Liu YH, He N, Zhang J, Zhou PH, Li M, Guan T and Liu JR: Tocotrienol-rich fraction (TRF) suppresses the growth of human colon cancer xenografts in Balb/C nude mice by the Wnt pathway. PLoS One 10: e0122175, 2015.

12. Ling MT, Luk SU, Al-Ejeh F and Khanna KK: Tocotrienol as a potential anticancer agent. Carcinogenesis 33: 233-239, 2012.

13. Gagic Z, Ivkovic B, Srdic-Rajic T, Vucicevic J, Nikolic K and Agbaba D: Synthesis of the vitamin E amino acid esters with an enhanced anticancer activity and in silico screening for new antineoplastic drugs. Eur J Pharm Sci 88: 59-69, 2016.

14. Liu B, Qu L and Yan S: Cyclooxygenase-2 promotes tumor growth and suppresses tumor immunity. Cancer Cell Int 15: 106, 2015.

15. Sun WH, Sun YL, Fang RN, Shao Y, Xu HC, Xue QP, Ding GX and Cheng YL: Expression of cyclooxygenase-2 and matrix metalloproteinase-9 in gastric carcinoma and its correlation with angiogenesis. Jpn J Clin Oncol 35: 707-713, 2005.

16. Huang JX, Xiao W, Chen WC, Lin MS, Song ZX, Chen P, Zhang YL, Li FY, Qian RY and Salminen E: Relationship between COX-2 and cell cycle-regulatory proteins in patients with esophageal squamous cell carcinoma. World J Gastroenterol 16: 5975-5981, 2010.

17. Wu BW,Li DF, Ke ZF, Ma D, Li YJ, Gang D, Zheng ZG, Zhang KJ and Zhang YH: Expression characteristics of heparanase in colon carcinoma and its close relationship with cyclooxygenase-2 and angiogenesis. Hepatogastroenterology 57: 1510-1514, 2010.

18. Krishnamachary B, Stasinopoulos I, Kakkad S, Penet MF, Jacob D, Wildes F, Mironchik Y, Pathak AP, Solaiyappan M and Bhujwalla ZM: Breast cancer cell cyclooxygenase-2 expression alters extracellular matrix structure and function and numbers of cancer associated fibroblasts. Oncotarget 8: 17981-17994, 2017.

19. Huang F, Lin C, Shi YH and Kuerban G: MicroRNA-101 inhibits cell proliferation, invasion, and promotes apoptosis by regulating cyclooxygenase-2 in Hela cervical carcinoma cells. Asian Pac J Cancer Prev 14: 5915-5920, 2013.

20. Li W, Sun D, Lv Z, Wei Y, Zheng L, Zeng T and Zhao J: Insulin-like growth factor binding protein-4 inhibits cell growth, migration and invasion, and downregulates COX-2 expression in A549 lung cancer cells. Cell Biol Int 41: 384-391, 2017.

21. Ram M, Sherer Y and Shoenfeld Y: Matrix metalloproteinase-9 and autoimmune diseases. J Clin Immunol 26: 299-307, 2006.

22. Nelson AR, Fingleton B, Rothenberg ML and Matrisian LM: Matrix metalloproteinases: Biologic activity and clinical implications. J Clin Oncol 18: 1135-1149, 2000.

23. Liu Z, Han L, Dong Y, Tan Y, Li Y, Zhao M, Xie H, Ju H, Wang $\mathrm{H}$, Zhao Y, et al: EGFRvIII/integrin $\beta 3$ interaction in hypoxic and vitronectinenriching microenvironment promote GBM progression and metastasis. Oncotarget 7: 4680-4694, 2016.

24. Sun W, Wang Q, Chen B, Liu J, Liu H and Xu W: Gammatocotrienol-induced apoptosis in human gastric cancer SGC-7901 cells is associated with a suppression in mitogen-activated protein kinase signalling. Br J Nutr 99: 1247-1254, 2008.

25. Siegel R, Naishadham D and Jemal A: Cancer statistics for Hispanics/Latinos, 2012. CA Cancer J Clin 62: 283-298, 2012.

26. Liu W, Yang Q, Liu B, Zhu Z. Serum proteomics for gastric cancer. Clin Chim Acta 431: 179-184, 2014.

27. Li Z, You K, Li J, Wang Y, Xu H, Gao B and Wang J: Madecassoside suppresses proliferation and invasiveness of HGF-induced human hepatocellular carcinoma cells via PKC-cMET-ERK1/2COX-2-PGE2 pathway. Int Immunopharmacol 33: 24-32, 2016.

28. Sun WH, Zhu F, Chen GS, Su H, Luo C, Zhao QS, Zhang Y, Shao Y, Sun J, Zhou SM, et al: Blockade of cholecystokinin-2 receptor and cyclooxygenase-2 synergistically induces cell apoptosis, and inhibits the proliferation of human gastric cancer cells in vitro. Cancer Lett 263: 302-311, 2008. 
29. Zhang H, Sun K, Ding J, Xu H, Zhu L, Zhang K, Li X and Sun W: Harmine induces apoptosis and inhibits tumor cell proliferation, migration and invasion through down-regulation of cyclooxygenase-2 expression in gastric cancer. Phytomedicine21: $348-355,2014$

30. Sun K, Tang XH and Xie YK: Paclitaxel combined with harmine inhibits the migration and invasion of gastric cancer cells through downregulation of cyclooxygenase-2 expression. Oncol Lett 10 : 1649-1654, 2015

31. Shin NR, Jeong EH, Choi CI, Moon HJ, Kwon CH, Chu IS, Kim GH, Jeon TY, Kim DH, Lee JH, et al: Overexpression of Snail is associated with lymph node metastasis and poor prognosis in patients with gastric cancer. BMC Cancer 12: 521, 2012 .
32. Velinov N, Poptodorov G, Gabrovski N and Gabrovski S: The role of matrixmetalloproteinases in the tumor growth and metastasis. Khirurgiia (Sofiia) 1: 44-49, 2010 (In Bulgarian).

33. Liu XJ, Chen ZF, Li HL, Hu ZN, Liu M, Tian AP, Zhao D, Wu J, Zhou YN and Qiao L: Interaction between cyclooxygenase-2, Snail, and E-cadherin in gastric cancer cells. World $\mathbf{J}$ Gastroenterol 19: 6265-6271, 2013.

34. Jiang H, Zhou Y, Liao Q and Ouyang H: Helicobacter pylori infection promotes the invasion and metastasis of gastric cancer through increasing the expression of matrix metalloproteinase-1 and matrix metalloproteinase-10. Exp Ther Med 8: 769-774, 2014. 